\title{
SUbJETIVAÇÃO E GOVERNAMENTALIDADE: QUESTÕES PARA A Psicologia
}

\author{
Alyne Alvarez Silva $\star$ \\ Ricardo Pimentel Méllo $\star \star$
}

\begin{abstract}
Resumo
Este ensaio discorre sobre os modos de subjetivação, dando visibilidade a modalidades de construção e de experimentação subjetiva, problematizando concepções tradicionais da noção de sujeito, que circulam nos cursos de Psicologia. Visa-se instigar discussões que se contraponham à reificação do ser humano como dotado de uma substância atemporal e sem significação política. Tem-se como suporte o conceito de governamentalidade e tecnologias de poder, como as "técnicas de si", discutidos por Michel Foucault. Neste sentido, a Psicologia pode ser instrumento para pesquisar essas tecnologias e compreender os movimentos de vida do ser humano ou simplesmente tornar-se parte delas, sem criticá-las.
\end{abstract}

Palavras-chave: modos de subjetivação; psicologia; governamentalidade.

\section{SUBJECTIVITY AND GOVERNABILITY: ISSUES FOR PSYCHOLOGY}

\begin{abstract}
This essay argues about the modes of subjectivity, emphasizing the construction and subjectivity experimentation modality and, at the same time, casting doubts on the traditional notions of subjectivity that are present in the Psychology programs. It has the aim to promote discussions to counterpointing the idea that the human beings are made of a substance that is timeless and without political significance. The arguments take support in the concept of governability and power's technologies, like the "me technologies", discussed by Michel Foucault. This way, the Psychology might be a tool to investigate these technologies and to comprehend the human life movements, or, it simply can become a part of them without criticism.
\end{abstract}

Keywords: subjectivity modes; psychology; governability.

^ Mestre em Psicologia pela Universidade Federal do Pará(UFPA), Professora do curso de Psicologia da Universidade da Amazônia (UNAMA), Doutoranda em Psicologia Social na Pontifícia Universidade Católica de São Paulo (PUC-SP), Membro do Núcleo Belém ABRAPSO.

E-mail: alvarezalyne@hotmail.com.

$\star \star$ Doutor em Psicologia Social (PUC-SP), Professor do curso de Graduação em Psicologia da Universidade Federal do Ceará; integrante do Núcleo de Práticas Discursivas e Produção de Sentidos (PUC-SP), Membro da Diretoria Nacional da ABRAPSO.

E-mail: ricardo_pm@uol.com.br. 
Só uma multiplicidade pode ser organizada em unidade. (MÜLLER-LAUTER, 1997, p. 74)

Não é possível, numa clave foucaultiana, pensar modos de subjetivação sem necessariamente atrelar tal temática à questão do "governo". Segundo Larrosa (1994), o binômio saber/poder na obra de Foucault, que já fora abordado em termos de disciplina e biopoder, ${ }^{1}$ passa a ser abordado em termos de "governo" a partir de $1978^{2}$ e desde o princípio a questão do governo está relacionada ao "autogoverno", que, por sua vez, relaciona-se ao tema da "subjetividade".

De uma forma geral, para iniciar algum entendimento acerca da estrita relação entre governo e "subjetividade", deve-se entender esta última como resultado de um contínuo processo de produção dirigido à geração de modos de existências, que inclui modos de agir, de sentir, de dizer o mundo. Para tanto, seria preciso abandonar a concepção de subjetividade "como substância, entidade dada desde sempre, naturalizada por leis universais estritamente psíquicas, que a regrariam e lhe assegurariam contornos conceituais bem delimitados e imutáveis", como nos sugere Tedesco (2006, p. 358). Deve-se passar a concebê-la como processualidade que se realiza num plano histórico-político, no qual o sujeito emerge como efeito de relações de poder.

Desprezando-se um suposto caráter imutável e estritamente psíquico da subjetividade, isto é, negando-a como um dado primordial e concebendo-a como processualidade que se realiza num plano histórico-político, pensa-se o sujeito como efeito que emerge de relações de produção política. Dessa maneira, são as relações de poder articuladas no decorrer da história, que se fazem presentes nas mais diversas práticas contemporâneas, que devem ser focos de atenção para compreender o que viemos nos tornando no decorrer de séculos de subjetivação, o que hoje somos e o que podemos deixar de ser.

Este ensaio discorre sobre os modos de subjetivação, processos a partir dos quais nos tornamos sujeitos em meio a relações de força materializadas em práticas que produzem subjetividade a partir do seu caráter político. Dando visibilidade a modalidades de construção e de experimentação subjetiva e problematizando concepções tradicionais da noção de sujeito, que circulam nos cursos de Psicologia, visa-se instigar discussões que se contraponham à reificação do ser humano como dotado de uma substância atemporal e sem significação política, somando-se, dessa maneira, às posições teóricas e ações políticas afinadas com a volatilidade do viver humano e não humano.

Aliás, também nos afinamos com posturas que vivem o humano como inseparável do que se costuma chamar de não humano (evitando a clássica divisão entre sujeito e objeto), postulando que vivemos hibridizados, como defendem Haraway (1996), Latour (1996), Preciado (2008). Esta postura alinha-se a um viés foucaultiano que está presente nas proposições de Rose (2001a e 2001b) e que nos permite entender o que chamamos de "processos de subjetivação" ou "modos de viver" por meio do estudo de técnicas, presentes nas relações sociais 
cotidianas que delimitam as nossas possibilidades práticas de viver. São estudos que buscam dar visibilidade aos meios de controle de corpos entendidos como materialidades tornadas humanas e não humanas.

Assim, temos de um lado, como apontou Foucault (1994a), correntes da Psicologia herdeiras do Iluminismo que, em diferentes medidas, colocam o humano em um jogo de saber-poder que o constitui essencializado por ser extensão de leis naturais, advindas de hipóteses explicativas e verificações experimentais. E, de outro, uma Psicologia incipiente que começa a mostrar seus incômodos com o que produziu ao longo de um século e que, portanto, faz emergir todas as contradições próprias de uma prática que nasceu para controlar, predizer e classificar e que agora deve reinventar seus postulados. Segundo o autor:

A renovação radical da psicologia como ciência do homem não é, portanto, somente um fato histórico cujo desenvolvimento possa situar-se nos últimos cem anos; ainda é uma tarefa incompleta que está por se cumprir e, neste sentido, permanece na ordem do dia. (FOUCAULT, 1994a, p. 01, tradução nossa).

Em outras palavras, a problematização da vida humana pode ser feita, grosso modo, de duas maneiras: buscando as evidências de suas caracterizações essenciais que lhe permitiriam ser consideradas humanas (busca-se a verdade do humano inclusive em posturas que dizem que a vida evolui ou muda no/com o tempo); outra tornando a própria pesquisa parte de uma política, entendendo que todo caminho de conhecimento do humano é político, na medida em que o traçado e a visibilidade (a escrita, determinada metodologia) fazem uma composição específica. Ao se falar do humano o compomos, ou seja, neste caso, não buscamos a verdade do humano, mas nos pautamos em uma espécie de questão-guia: a qual humano damos vida quando falamos deles/neles, quando pesquisamos eles/ neles e vivemos eles/neles?

Como damos vida ao humano? Que práticas instituímos nesse processo e quais as que buscamos evitar? Trata-se então de uma política de pesquisa (e de vida) que estabelece as relações de poder, sujeitando o humano a uma prática ou a uma forma de governo (portanto, de gerência da vida), chamada por Foucault (1979) de "governamentalidade" e sempre feita em práticas (de poder).

Ao final do ensaio, exemplificamos esse processo a partir da posição de Larrosa (1994) acerca da educação e das práticas "psi”, por meio de práticas pedagógicas e terapêuticas que, em vez de serem pensadas como espaços de possibilidades para as pessoas se "desenvolverem" ou se "recuperarem", são postas como práticas produtoras de subjetividades, capazes de estabelecer, regular e modificar as relações dos sujeitos consigo mesmos. 
Em suma, faz-se a relação entre subjetivação e governamentalidade no intuito de pesquisar como as formas de dominação política encontram nas subjetividades, aqui entendidas como maneiras de viver, um terreno privilegiado de atuação e como outras formas de pensar/praticar o sujeito conseguem escapar às capturas das tramas de saberes e poderes que perpassam esse processo.

A partir dessas premissas, dividimos este texto em dois itens expostos a seguir. No primeiro, pontuamos criticamente a concepção de ser humano como dotado de um "eu" centrado e uno, fundado como organismo biológico, concepção fundamental para a constituição/emergência da Psicologia. No final deste item, buscamos mostrar que houve um movimento crescente, a partir da metade do século XX, que se contrapôs a essa concepção. No item seguinte, ampliamos os questionamentos, tendo como suporte o conceito de governamentalidade, discutindo assim sobre o governo de si e das populações e argumentando sobre a importância de estudar as "tecnologias de si" a partir das quais cada ser humano se relaciona consigo mesmo colocando-se como objeto de saber para si próprio. Nesse aspecto, a Psicologia pode ser instrumento para pesquisar estas tecnologias e compreender os movimentos de vida do ser humano ou simplesmente fazer parte delas sem criticá-las.

\section{Das CONCEPCÕ̃es de "EU" AO DESCENTRAMENTO do SUJEITO}

A Psicologia surge como disciplina científica no final do século XIX e início do XX atrelada à necessidade de respaldar a atuação do poder disciplinar, que desde o fim do século XVIII se constituía em práticas de controle e adequação dos indivíduos aos aparelhos de produção, correção e/ou normalização (FIGUEIREDO; SANTI, 2004; PRADO FILHO; TRISOTTO, 2007). Assim, a Psicologia, a partir de seu saber científico, passou a legitimar em conjunto com outras Ciências Humanas, práticas disciplinares por meio de classificações, do estabelecimento do que é certo e errado, do que é normal e do que não é, respaldando o poder disciplinar na gestão das forças, tempos e saberes dos indivíduos.

A Psicologia e as chamadas Ciências Humanas criam, então, técnicas em íntima relação com saberes que identificam o ser humano - antes dotado de "alma" divina dada por seu Deus, seu criador, passa agora a ser dotado de psique advinda do "bios" - como organismo vivo. Assim, a ciência troca a religião pela biologia, aqui entendida em seu sentido amplo: estudo da estruturação da vida humana, desenvolvimento, funcionamento, reprodução, até a busca de estudos estatísticos da distribuição da "população", dividindo-a em classes, gênero, cultura, países etc. Com o intuito de não parecer biologicista demais, há áreas da Psicologia que acrescentam termos ao "bio", como se desejassem afirmar estruturas a ele inerentes, mas ainda usufruindo do "carro-chefe" da biologia, afirmando assim o ser humano como "bio-psico-social". Tendo como metáfora um trem, vemos que a locomotiva (bio), puxa os vagões divididos na segunda (psico) e terceira classes (social). 
Dessa maneira, a Psicologia surge com a finalidade de produzir um conhecimento positivo sobre o indivíduo, dispondo-o em uma estrutura, para falar da "verdade" (a partir do exame da tal estrutura), "inerente" aos seres humanos. Reifica-os como seres psicológicos dotados de um domínio interior pronto para ser explorado a partir de procedimentos e técnicas de autoconhecimento e autocontrole e, com isso, amplia o governo das populações. A Psicologia segue, então, a técnica do exame, tornando-a condição necessária a uma vida de qualidade. A vida, por sua vez, passa a girar em torno da busca por um conjunto de "traços psicológicos" que se confundem com traços morais, mais conhecidos como índole e caráter ou mesmo personalidade, que deveriam ser atributos de uma vida virtuosa. É difícil, sob esta ótica, separar o trabalho do psicólogo de um juízo moral ou doutrinal (leis gerais que regem o ser humano).

Destarte, o sujeito construído como cartesiano, moderno, racional, soberano, iluminista, enfim, aquele que Foucault anunciou ter morrido, foi e ainda é, de certa forma, reafirmado pelas chamadas "práticas psi" em termos de sua suposta "individualidade" e "identidade". Vale lembrar que quando Foucault anuncia a morte do sujeito, ele o faz, segundo Prado Filho (2005, p. 42), no sentido de não mais poder considerá-lo "como centro do pensamento, como ponto de partida, como categoria a priori e transcendental do conhecimento, [já que] este é uma produção histórica [...], uma ilusão, um autoelogio humano, demasiado moderno". Parafraseando Nietzsche, temos neste caso um humano, demasiado humano.

Segundo Rose (2001a), as sociedades modernas e ocidentais - que para alguns autores (Cf. FIGUEIREDO; SANTI, 2004) têm como marco o pensamento de René Descartes - são excepcionais na construção da pessoa:

[...] como um eu, como uma entidade naturalmente singular e distinta. [...] como esse locus natural de crenças e desejos, como algo dotado de capacidades inerentes, como a origem autoevidente das ações e das decisões, como fenômeno estável que se mostra através de diferentes contextos e diferentes épocas (ROSE, 2001a, p. 33).

Essa forma tão "natural" de nos pensarmos como sujeitos com tais características começou a ser construída no século XVI, na passagem do Renascimento para a Idade Moderna, e foi consolidada no século XVIII, no Iluminismo. Figueiredo e Santi (2004) colocam que, apesar dessa experiência que temos com relação a nós mesmos ser tão óbvia, estudos históricos e antropológicos apontam que nas sociedades não ocidentais essas experiências acontecem em níveis diferenciados.

Tal concepção de ser humano também foi criticada, no mesmo movimento em que foi concebida, entre alguns filósofos iluministas como Hume e Kant, que chegam a negar a estabilidade do "eu" e a própria soberania do sujeito, sua "autonomia", em virtude de que os desejos e os impulsos não poderiam ser definitivamente domados pela razão (FIGUEIREDO; SANTI, 2004). O movimento romântico, que nasceu como uma crítica ao Iluminismo no fim do século XVIII, apesar de ter dado continuidade à valorização da individualidade e intimidade, 
foi "um momento essencial na crise do sujeito moderno pela destituição do "eu' de seu lugar privilegiado de senhor, de soberano" (FIGUEIREDO; SANTI, 2004, p. 36). Mas talvez quem mais tenha conseguido ferir essa noção de "eu" tenha sido Nietzsche ao colocar o "eu" e o "sujeito" como ficções, frutos de criações humanas construídas num determinado momento com uma determinada finalidade: "a crença em algo fixo e estável seria uma necessidade humana, na tentativa de crer que tem controle sobre o devir" (FIGUEIREDO; SANTI, 2004, p. 38). Nietzsche contrapõe o apolíneo (deus da bela forma, da individuação, do domínio de si), ao dionisíaco (deus do excesso, da embriaguez, do imponderável, múltiplo) (Cf. MARTON, 1999).

Os autores que vêm anunciando a morte desse sujeito desde a segunda metade do século XX, na chamada "modernidade tardia" (HALL, 2006; SPINK, 2004), "modernidade reflexiva" (BECK, 1993) ou "pós-modernidade" (HARVEY, 1992), consideram o sujeito deslocado de seu suposto centro, pensam-no descentrado e, ao invés de estável, único e totalizado, pensam-no mutante, múltiplo e fragmentado. Não se deve perder de vista que tal deslocamento não deixa de propor outra noção de sujeito, promovendo necessariamente outros modos de ser, mas não intenta encerrá-lo conceitualmente em virtude de considerar, antes de tudo, o seu caráter mutante, os seus devires. Para Hall (2006), esse deslocamento na concepção do que seja o humano se dá em função de uma série de rupturas no discurso do conhecimento moderno.

Vale aqui situar historicamente esse deslocamento, apontando de modo breve os cinco avanços na teoria social e nas ciências humanas, descritos por Hall (2006), responsáveis em grande parte pelo "descentramento" final do sujeito cartesiano. O primeiro deles refere-se às tradições do pensamento marxista, pois quando Marx afirma que "os homens (sic) fazem a história, mas sob as condições que lhes são dadas" (HALL, 2006, p. 34), retira do sujeito moderno, que tudo controla e domina, o seu lugar de soberano onipotente. Dessa maneira, Marx deslocou duas proposições-chave da filosofia moderna: que há uma essência universal de homem e que esta essência é atributo de cada indivíduo singular.

Seguindo os grandes "descentramentos" no pensamento ocidental do século XX descritos por Hall (2006), o segundo deles trata da "descoberta" do inconsciente por Freud, que arruína o conceito de sujeito cognoscente e racional dotado de uma identidade fixa e unificada, como era o sujeito concebido por Descartes. Nossos modos de ser, sexualidade e desejos passam a ser entendidos como constituídos com base em processos psíquicos e simbólicos inconscientes.

$\mathrm{O}$ terceiro deslocamento diz respeito aos trabalhos do linguista Ferdinand de Saussure, que retira das pessoas a autoria de suas afirmações na medida em que considera a língua como um sistema social e não individual, como um conjunto de sentidos que preexistem a nós; bem como retira das palavras possíveis significados fixos, já que "as palavras sempre carregam ecos de outros significados que elas colocam em movimento" (HALL, 2006, p. 41). Os significados das coisas passam a ser considerados instáveis, inesgotáveis, tirando-nos, assim, a possibilidade de se criar mundos fixos e estáveis. 
Hall (2006) aponta o trabalho de Michel Foucault como o quarto e principal descentramento da identidade e do sujeito no pensamento ocidental do século passado em virtude da sua "genealogia do sujeito", em que descreve os efeitos do poder disciplinar na fabricação de sujeitos disciplinares e do biopoder na regulação das populações.

Por fim, o autor fala do movimento feminista, como crítica teórica e movimento social. Esta seria a quinta teoria a provocar impacto nas concepções do sujeito cartesiano, descentrando-o. Além do questionamento da distinção dicotômica entre "dentro" e "fora", "público" e "privado" e da posição social das mulheres, voltou-se para a formação das identidades sexuais e de gênero, desnaturalizando as concepções identitárias para cada gênero (HALL, 2006).

Conceber o ser humano como descentrado, deslocado do seu suposto centro e, portanto, mutante, múltiplo e fragmentado, nos possibilita entender o processo de constituição das subjetividades de modo diferente. "No lugar do eu, proliferam novas imagens de subjetividade: [...] descentrada, múltipla, nômade; como resultado de práticas episódicas, em locais e épocas particulares" (ROSE, 2001b, p. 140). A "identidade" passa ser entendida a partir de processos múltiplos de formação e transformação que ocorrem continuamente em relação às formas pelas quais seríamos interpelados nos sistemas culturais que nos rodeiam. Para Hall (2006, p. 13):

À medida que os sistemas de significação e representação cultural se multiplicam, somos confrontados por uma multiplicidade desconcertante e cambiante de identidades possíveis, com cada uma das quais poderíamos nos identificar - ao menos temporariamente.

Vale dizer que já não é mais interessante falar de como nos tornamos sujeitos em termos de "identidade" em virtude de remeter a uma noção essencialista de ser humano e de essa noção agenciar aparatos de regulação e sujeição dos indivíduos. No dicionário, "identidade" significa "qualidade de idêntico" ou ainda "os caracteres próprios e exclusivos duma pessoa" (FERREIRA, 2000, p. 371). Portanto, falar que temos uma "identidade" inevitavelmente nos remete àquilo que é "idêntico", aquilo que pertenceria a nossa suposta natureza.

Mesmo Hall (2006), em A identidade cultural na pós-modernidade, pondera, apesar do título do livro, que não se deveria falar de identidade, mas de identificação, remetendo-se a sua processualidade. Embora ainda ancorado de alguma forma na noção de identidade, o autor nos ajuda a entender o deslocamento da noção de "eu" a partir dos descentramentos apontados, o que nos possibilita chegar mais facilmente ao entendimento de como Rose, baseado em Deleuze e Guatarri (1995), nos propõe ver os sujeitos de uma forma ainda mais intrigante: "É como 'agenciamentos' que metamorfoseiam ou mudam suas propriedades à medida que expandem suas conexões: eles não 'são' nada mais e nada menos que as cambiantes conexões com as quais eles são associados" (ROSE, 2001b, p. 146). 


\section{SubJetivaÇão E Governamentalidade}

Nikolas Rose (2001b) afirma que, apesar da "morte do sujeito" ter sido anunciada, a forma de concebê-lo como dotado de uma identidade ou interioridade continua sendo politicamente interessante para o funcionamento de estratégias de assujeitamento, pois acreditar num ser humano como um indivíduo consciente de todas as suas ações e, portanto, unicamente responsável por suas escolhas e decisões é uma maneira muito conveniente de concebê-lo do ponto de vista do "governo".

Essa solidificação do indivíduo se faz presente no cotidiano de modos diversos, todos atribuindo responsabilidade (culpa) ao indivíduo pelos seus atos e omissões, seja por argumentações biológicas do tipo: "isso ocorre por causa de sua herança genética", seja por argumentações psicológicas do tipo: "isso ocorre por causa de sua personalidade, caráter", ou ainda, devido a atributos advindos de suas relações (argumentações sociológicas), quando se diz, por exemplo, "veio de uma família desestruturada", "não teve educação adequada" ou "é por causa da cultura onde está inserido". Queremos dizer que, seja pautando-se em uma tradição biológica, psicológica ou mais sociológica, é possível que permaneçam os saberes que podem sustentar, igualmente, uma economia de governo que visa administrar a população "com sutileza e administrá-la em detalhe" (FOUCAULT, 2008, p. 142). Foucault chamou essa economia de poder pastoral: "um poder que se exerce mais sobre uma multiplicidade do que sobre um território. [...] É, enfim, um poder que visa ao mesmo tempo todos e cada um..." (FOUCAULT, 2008, p. 173).

Michel Foucault e Nikolas Rose nos fazem pensar na forma como muitas vezes se vive o que se acredita "ser" o humano como base para respaldar e justificar a existência de vários aparatos de regulação da conduta. Se não entendermos o humano em termos de responsabilidade e intenção (seja por efeito genético ou relacional), algumas instituições deixam de fazer sentido como, por exemplo, o sistema penal. Para Rauter (2003, p. 28):

A ideia de que o fundamento das leis é a existência de um contrato social firmado entre os membros da coletividade implica a concepção de que os homens têm esta capacidade racional de decidir sobre seus atos. Considerados como partes responsáveis neste contrato, é em virtude desta mesma responsabilidade que podem ser punidos, se 'decidirem' pela violação dos mesmos.

Rose (2001b), apoiando-se nas concepções foucaultianas e, portanto, contrapondo-se aos chamados "universais antropológicos", 3 denuncia o forjamento da concepção do ser humano como sujeito psicologizado, interiorizado, unificado e totalizado, e o concebe como o resultado do intercruzamento de práticas, técnicas ou tecnologias de ordens diversas capazes de fazê-lo relacionar consigo mesmo de uma maneira específica e se pensar como sujeito de um tipo específico, mas, de todo modo, um tipo que encontra referências universais. 
Com a finalidade de investigar as práticas nas quais as pessoas são compreendidas e nas quais se age sobre elas, Rose (2001a) propõe uma genealogia ${ }^{4}$ da subjetivação, que seria uma genealogia das relações que os seres humanos estabelecem consigo mesmos a partir de práticas que os fazem se pensar como "eus". Segundo o autor, para que a investigação das dimensões das nossas relações com nós mesmos seja tratada da perspectiva do "governo" é preciso considerar que tal relação tem determinada forma por estarmos inseridos em — ou por sermos objetos de - esquemas mais ou menos racionalizados que nos fazem compreender nossa existência em função de certos objetivos referentes a "regimes de pessoa". Estes regimes seriam posições identitárias prescritas, às quais somos de certa forma compelidos a nos identificar e a agir em função delas. Por exemplo: masculinidade, feminilidade, honra, boa conduta, civilidade, disciplina, eficiência, harmonia, sucesso, cidadão, paciente, marido, mulher, filho etc.

Esses regimes de pessoa são formas de poder que nos individualizam na medida em que nos conformam a certos padrões de modos de viver, bem como, nos conformam a certa "identidade" que nos fazem agir por pressupostos que, além de nos caracterizar (dentro das variâncias de padrões universais), nos fazem viver como dotados de uma interioridade. Assim, todos e todas constroem uma narrativa sobre si, que se pretende coerente e progressiva, que visa ao equilíbrio e à adaptação, como em geral nos ensina a "psicologia do desenvolvimento". Como se o mundo pudesse ser captado por um aparelho intelectual que amadurece em função do desenvolvimento biológico e social. Vamos passando por fases, como se houvesse um progresso, ou seja, assim como crescemos em tamanho, também o faríamos em inteligência e em responsabilidade por nós mesmos. Trata-se de uma metáfora da maturação biológico-psíquica-social.

Os saberes sobre nós e o mundo (tornando-os categorias distintas) convertem-se em verdades nas quais deslizamos a nossa vida (algumas vezes sem muitos deslocamentos, ou só aqueles que permitem sermos sempre idênticos). Os acasos e acidentes tornam-se "fatos" devidamente relacionados como "justificativas razoáveis". Até o múltiplo é descrito como se fosse uma unidade apenas diferente do hegemônico. Por exemplo, mesmo quando dizemos que o ser humano é "biopsico-social", ainda não falamos que ele é múltiplo, transversal, incoerente, mas o dotamos de uma junção de categorias que "interagem entre si" e finalizamos justificando essa maneira de exposição dos modos humanos de ser, como sendo "didática", já que são inseparáveis, como se essa explicação bastasse a si mesma, ou seja, um conceito tão importante como a "dialética" acaba por ser usado para encerrar discussões. Assim, mesmo quando não conseguimos classificar algo por fugir à "coerência" ou ao "bom senso" (que dá no mesmo), ainda assim o fazemos sem argumentações. A discussão encerra-se dizendo-se: "trata-se de uma relação dialética entre o sujeito e o meio, entre o biológico e o social, entre o indivíduo e a sociedade". (Isso é comum entre diversas posições teórico-metodológicas na Psicologia, às vezes só substituindo as palavras: ontogênese, filogênese e cultura). ${ }^{5}$ 
Como exemplo do múltiplo descrito como unidade e de nossa dificuldade de escapar das sínteses que o excluem, citamos o conceito de "abjeto" discutido por Butler (2008). A autora se refere a este conceito dando o exemplo de pessoas que não são reguladas por práticas identificatórias da materialização de um gênero, exclusivamente, vivido (performaticamente) como masculino ou feminino e que, portanto, são tratadas como abjetas. Quem não "se faz" na performance "bio-piso-social" naturalizada pelos saberes é classificado como diferente, como se "todos os outros" fossem iguais. Os diferentes, múltiplos, são abjetos.

A busca de uma linha de "coerência" é regulada pela vontade de verdade que Foucault (1996, p. 14) indicou como sendo "um sistema de exclusão (sistema histórico, institucionalmente constrangedor)" que atinge as práticas discursivas. Cria-se um acontecimento (por exemplo, a anatomia do corpo que busca delimitar gêneros) que tem efeito de exclusão, abjeção. É importante lembrar que o "psico" e o "social" também se tornam acontecimentos que, de algum modo, materializam a vida humana, dando certo contorno a ela. Butler (2008) lembra que cada uma dessas categorias tem história que constituem linhas de fronteira, a nosso ver, não só para delimitar nossos corpos, mas nossas vidas como um todo. As fronteiras que estabelecemos categorizam o que deve ser excluído, não obstante sempre presente como um indicativo do que devemos evitar.

Zamora (2008) nos fala dessa despotencialização da vida em termos de biopoder que, engendrado, por exemplo, pelo capitalismo mundial, fabrica individualidades em série, subjetividades indiferenciadas como efeito dos "desejos de manicômio, desejos de subjugar, de classificar, de controlar, de oprimir" (MACHADO; LAVRADOR, 2001 apud ZAMORA, 2008, p. 111).

No entanto, para dar visibilidade à fabricação de modos de ser, não se pode reduzir os processos de institucionalização do "eu" às relações de poder que disciplinam e regulamentam a vida humana apenas como técnicas para o "governo dos outros", visto que as "tecnologias de si" somam meios para o "governo de si”. Para Foucault (1997), o sujeito é estabelecido, em diferentes momentos e contextos institucionais, como objeto de um saber desejável e até indispensável. Mas o autor sugere que se volte a atenção às "tecnologias de si", posto que estas são responsáveis pela forma como o sujeito se relaciona consigo mesmo, o que, por sua vez, o coloca como objeto para si próprio. $\mathrm{O}$ autor define as tecnologias ou técnicas de si como:

[...] os procedimentos, [...], pressupostos ou prescritos aos indivíduos para fixar sua identidade, mantê-la ou transformála em função de determinados fins, e isso graças a relações de domínio de si sobre si ou de conhecimento de si por si (FOUCAULT, 1997, p. 109).

Dessa maneira, o imperativo "conhecer-se a si mesmo", tão "natural" (FOUCAULT, 2004) nas sociedades ocidentais modernas, em virtude da concepção de ser humano que foi capaz de tecer, passa a ser enfrentado como experiência e técnica elaborada capaz de transformar essa experiência. É importante 
pontuar que as "práticas psi" tomam um lugar exímio com relação à atitude de promover uma relação do sujeito com ele mesmo, de fazê-lo voltar-se para "si" como uma ferramenta para o "autoconhecimento".

As técnicas de si seriam, então, procedimentos ou mecanismos capazes de colocar em funcionamento certas operações do sujeito com relação a ele mesmo. E, se são capazes disso, tornam-se, então, dispositivos ou ordenadores de efeitos. Isso resulta na forma como se experimenta a vida como uma vida "de si". Assim, saber e poder colados criam o efeito de "uma subjetividade": "o modo no qual o sujeito faz a experiência de si mesmo em um jogo de verdade no qual está em relação consigo" (FOUCAULT, $1984^{6}$ apud LARROSA, 1994, p. 55). Nas palavras de Larrosa (1994, p. 43), "experiência de si" seria:

[...] o resultado de um complexo processo histórico de fabricação no qual se entrecruzam os discursos que definem a verdade do sujeito, as práticas que regulam seu comportamento e as formas de subjetividade nas quais se constitui sua própria interioridade. [...] A experiência de si, historicamente constituída, é aquilo a respeito do qual o sujeito se oferece seu próprio ser quando se observa, se decifra, se interpreta, se descreve, se julga, se narra, se domina, quando faz determinadas coisas consigo mesmo etc. E esse ser próprio sempre se produz com relação a certas problematizações e no interior de certas práticas.

Entre as "técnicas de si" e a "experiência de si”, há, então, uma relação estrita, tendo em vista que esta é resultado daquelas quando contextualizadas em termos históricos e práticos. Falando de outra maneira, a experiência de si seria "a correlação, em um corte espaço-temporal concreto, entre domínios de saber, tipos de normatividade e formas de subjetivação" (LARROSA, 1994, p. 57).

Rose (2001a, p. 37), para responder a questão "que meios têm sido inventados para governar o ser humano, para moldar ou orientar sua conduta nas direções desejadas e como esses programas têm buscado corporificá-las sob certas formas técnicas", define o que seriam as tecnologias "humanas" a partir de dois tipos de relação complementares capazes de pôr em funcionamento as técnicas de si: as relações disciplinares e as relações pastorais.

O primeiro tipo de relação coloca a tecnologia como sinônimo de agenciamento ou dispositivo, o qual seria um conjunto de práticas híbrido (de pessoas, prédios, leis, saberes, regulamentos, sistemas de julgamento, instrumentos etc.), em que uma trama de saberes e um feixe de forças lhes são imanentes. Este conjunto é orientado por determinados pressupostos e objetivos para agirem sobre os seres humanos. Esse tipo de tecnologia diz respeito às instituições disciplinares descritas por Foucault (1987), comentado acima em termos de poder disciplinar, que funcionam por meio da sistematização detalhada do espaço, do tempo e das relações entre os indivíduos; da manipulação de cada gesto, da observação vigi- 
lante e controladora dos corpos e de uma avaliação normalizadora. Tais instituições fazem com o que os indivíduos tomem para si certo sistema de julgamento para que sejam capazes de conduzir suas próprias vidas de forma desejável.

Dentro de uma instituição disciplinar, como um centro de internação para adolescentes, por exemplo, haverá sempre regras para gerir o tempo (hora para acordar, para almoçar, para estudar, para praticar esporte, para falar e calar), bem como regras que regularão seus pronunciamentos e as atitudes (quem deve falar, o que deve ser dito, em que momento, para quem e para quê; o que é permitido fazer e o que é proibido, em que espaços etc.). E são as atitudes e os pronunciamentos que servirão de critério para a constante avaliação que os adolescentes internados sofrerão.

Já a relação pastoral, estabelecida entre uma figura de autoridade e um indivíduo que "precisa" ser orientado e aconselhado, estabeleceria no indivíduo procedimentos de "autoinspeção, autossuspeição, exposição do eu, autodeciframento e autoformação" (ROSE, 2001a, p. 38) a partir de técnicas às vezes consideradas "simples", como a confissão, por exemplo. Pode-se entender a relação pastoral como uma relação de poder pautada no que é estabelecido entre um pastor e seu rebanho, na qual a obediência e a responsabilidade são princípios básicos para a condução do último num caminho desejável pelo primeiro e em troca do sacrifício deste.

No entanto, para que o pastor - ou quem quer que ocupe este lugar guie condutas, é necessário que se faça uso de determinadas tecnologias de si, capazes de fazer cada membro do seu rebanho criar uma relação consigo mesmo, estabelecendo verdades sobre si no mesmo momento em que se constitui nessas verdades e as comunica ao seu pastor. Além da confissão, o exame de consciência e a direção de consciência são técnicas específicas deste poder desenvolvido entre os hebreus no início do primeiro milênio e retomado com o surgimento dos Estados Modernos e a necessidade de estabelecer individualidades (FOUCAULT, 2006). As relações terapeuta-cliente/paciente, pedagogo-educando, médico-paciente, pároco-fiel, pais-filhos, são exemplos desse tipo de relação.

Vale ressaltar que quem inventa essas relações não é o Estado ou um grupo que articula isso em uma sala midiática. É o movimento das forças sem sujeitos, ou seja, quando Foucault emprega o termo sujeito, não está se referindo a um corpo com interioridade, a uma espécie de psique que usa o nosso corpo. Ele (FOUCAULT, 1995) atribui dois significados à palavra sujeito: (1) "sujeito a alguém pelo controle e poder, e (2) preso à sua própria identidade por uma consciência ou autoconhecimento". Tanto um como o outro sugerem uma forma de poder que subjuga e torna o ser humano sujeito a alguém ou alguma coisa.

Não se trata, portanto, da constituição de uma identidade, de uma pessoa ou, menos ainda uma pessoalidade se isto significa a "qualidade de uma pessoa", seu "caráter". Mas entender que não há um sujeito prévio ao processo de subjetivação. Ele toma visibilidades no processo. Viver só é possível para o humano moderno se dobrar-se às forças. Ao mesmo tempo, não poderá deixar de continuar sendo transpassado por outras que ainda não dobrou. Assim, a vida como uma 
arte, é menos a palavra vazia da transgressão (que pode ser conservadora de certa força) e mais a "ética constante do descompromisso com formas constituídas de experiência, de libertação pessoal para a invenção de novas formas de vida" (RAJCHMAN, 1985 apud LEVY, 2003, p. 88).

Sendo assim, "o poder disciplinar não pode ser identificado a uma instituição nem a um aparelho, porque é um tipo de poder, uma tecnologia, uma modalidade de poder encontrada em instituições de natureza e objetivos bastante diferentes" (MACHADO, 2009, p. 187). Mas podemos dizer que a instituição consegue tornar-se um acontecimento na junção de saberes e poderes que lhe soerguem e lhe sustentam. Assim, a Psicologia se mantém, favorecendo tecnologias de ensimesmamento de sujeitos. Sua técnica fundante é o exame, o mergulho na "memória", que Machado (2009, p. 177) conceitua como "o verdadeiro nome da relação consigo mesmo". O apelo ao exame introspectivo e, ao mesmo tempo, retrospectivo, peculiariza um trabalho que não é só da Psicologia, mas até mesmo da polícia que deseja refazer o crime tal qual ocorreu. Assim, a Psicologia busca em seu trabalho um efeito de verdade, que afirma advir do encontro do sujeito consigo mesmo. Em vez de propor a invenção de si, não poucas vezes, propõe a representação, regulação, identificação do mesmo, ou o eterno retorno do mesmo. Esse trabalho é solidificado por um regime de verdade que une: poder-ciência / saber psicológico / instituição clínica (ou outro espaço psi).

Nessa perspectiva, a subjetividade seria, então, resultado das tecnologias constituídas por práticas que atravessam relações e que criam modos de viver que funcionam como guias, sendo visualizados como aspirações, pensamentos, ambições e ações de sujeitos com o desígnio de lhes estabelecer fins considerados desejáveis (SÁNCHEZ; MARTÍNEZ; RICO, 2006). Weinmann (2006, p. 17) diz que olhar essas tecnologias como práticas que fazem dos sujeitos seus objetos, é "analisar uma operação de assujeitamento, que ao mesmo tempo em que enuncia a verdade de um sujeito, o liga coercitivamente, a uma determinada identidade". Portanto, o assujeitamento não é especificamente a repressão do Estado ou do capitalismo exercida sobre um sujeito, como se aqueles fossem entidades que se sobrepõem a este. São relações de práticas de poder. Quando Foucault nos alerta para isso e introduz o conceito de "biopoder" (e como apontamos acima exemplificado com o poder pastoral), busca defender, como explicita Machado (1982, p. XVI) que:

Não se explica inteiramente o poder quando se procura caracterizá-lo por sua função repressiva. O que lhe interessa basicamente não é expulsar os homens da vida social, impedir o exercício de suas atividades, e sim gerir a vida dos homens, controlá-los em suas ações para que seja possível e viável utilizá-los ao máximo, aproveitando suas potencialidades [...]. 
Por isso a importância da relação entre saberes e poderes que circulam na sociedade humana. Não é que um saber influencia alguém, mas o saber tem poder de gerir, de administrar a vida. Para que isso aconteça criamos estratégias. $\mathrm{Ou}$ seja, as positividades do poder são de produzir maneiras de viver e as estratégias para que elas subsistam.

Larrosa (1994), também em uma clave foucaultiana, enfatiza uma espécie de fabricação de sujeitos em meio a práticas ditadas pelos fazeres da ciência, como as práticas pedagógicas e terapêuticas. Estas não podem deixar de reconhecer que são mediadoras e produtoras de "modos de viver" (de "subjetivações"), embora geralmente se pautem na noção do sujeito iluminista (HALL, 2006): pessoa equipada de uma "essência verdadeira" que deve ser "descoberta", "desenvolvida" ou "recuperada" por seus intermédios. Para tais práticas, o sujeito teria sua autodeterminação "naturalmente" desenvolvida a partir de práticas pedagógicas e sua "verdadeira consciência de si" "recuperada" por práticas terapêuticas.

Ambas as práticas operam técnicas e saberes que propõem "autorreflexão", "tomada de consciência", "educação moral", "autoconhecimento", objetivando "instalar" nos sujeitos valores, atitudes, disposições, componentes afetivos etc. como características próprias da sua maneira de ser. Para Larrosa (1994), é justamente na articulação de práticas discursivas pedagógicas e terapêuticas (práticas psi) que o sujeito seria constituído como ser reflexivo capaz de se relacionar consigo mesmo: seria nessa articulação que se oferece ao sujeito a "experiência de si". A narrativa de si (confissão) passa a ser uma tecnologia fundamental na articulação dessas práticas. Em relação às técnicas terapêuticas em geral, certa narrativa de si deixa de ser vista como uma dentre várias outras que se referem a experiências de si e torna-se, no campo da representação, uma espécie de verdade de si, algo que revela a verdadeira identidade/personalidade de alguém. A verdade de si, na narrativa cria uma espécie de "mito de origem" do si. Ou seja, a narrativa vai à busca das origens finais do sujeito ou dos seus problemas (o que também dá no mesmo).

As práticas pedagógicas e terapêuticas atuam partindo de um conjunto mais ou menos integrado de concepções de sujeito, de teorias sobre a chamada natureza humana, a partir das quais avaliam as formas de relação que a pessoa é capaz de estabelecer consigo mesma como critério que a indicará como plenamente desenvolvida, madura e sã ou o seu inverso (desequilibrada, imatura ou mesmo doente). Esses seriam os discursos-saberes-práticas de verdade que norteariam a forma de uma pessoa se narrar, se julgar, se controlar e de se constituir como sujeito. Dessa maneira, essas práticas deveriam deixar de ser consideradas "espaços institucionalizados, onde a verdadeira natureza humana pode desenvolver-se ou recuperar-se" (LARROSA, 1994, p. 44), para também poderem ser analisadas como espaços institucionalizados onde se gerencia maneiras de viver.

Larrosa (1994), denunciando a educação de uma forma geral como uma prática disciplinar de normalização e controle social, afirma que as práticas pedagógicas e terapêuticas tratam de produzir e mediar certas "formas de subjetivação" nas quais se estabeleceria e se transformaria a "experiência de si". Assim, o 
sujeito pedagógico seria resultado do entrecruzamento de saberes que o nomeiam nos discursos pedagógicos (que se pretendem científicos) e nas práticas institucionalizadas que o capturam.

Vimos apontando certos modos de subjetivação - quer dizer, modos nos quais nos tornamos sujeitos - a partir de algumas tecnologias (disciplinares e pastorais), presentes em certas práticas (as pedagógicas e terapêuticas), voltadas para o governo do outro, daquele que precisa ser governado. No entanto, deve-se frisar, mais uma vez, que os modos de subjetivação não se encerram em práticas institucionais, práticas de poder ou práticas discursivas exteriores ao sujeito, já que estas (e diversas outras) devem ser eficientes ao "induzir" o sujeito a tomar para si a necessidade de se controlar, se comportar, de agir de determinada forma, utilizando-se das técnicas de si (descritas no início do tópico), que, em consonância com as demais práticas citadas, serão capazes de tecer uma experiência de si.

Todas essas concepções surgem atreladas aos pontos desenvolvidos por Foucault com relação à genealogia da arte do governo, entendendo "governo" como programas e estratégias elaboradas e prescritas para a "conduta da conduta" que são exercidos por meio de "racionalidades políticas (...) na qual o governo se torna uma questão de gerenciamento calculado das questões de cada um e de todos a fim de se alcançar objetivos desejáveis" (FOUCAULT, 1991 apud ROSE, 2001a, p. 41). Vale ressaltar que a arte de governar não se restringe ao governo em sua forma política, ao governo de Estado, como apontamos acima, mas "a práticas múltiplas, na medida em que muita gente pode governar: o pai de família, o superior do convento, o pedagogo e o professor em relação à criança e ao discípulo. Existem, portanto, muitos governos [...]" (FOUCAULT, 1979, p. 280).

Foucault (1994b, p. 03) conceitua "governamentalidade" como "encontro entre as técnicas de dominação exercida sobre os outros e as técnicas de si". Governar condutas, nesse sentido, é dirigir condutas, sejam estas as próprias condutas e/ou de outros e esse governo se dá em jogos estratégicos de poder e liberdade.

Nessa perspectiva, "governo", "autogoverno" e "subjetivação" se relacionam na medida em que é exigido de todos e cada um que, além de atos de obediência e submissão, também "atos de verdade". Nestes, o sujeito deve dizer não apenas "a" verdade, mas "uma" verdade a propósito de si mesmo. Quer dizer, além da necessidade de exercitar formas de vida determinadas, elas devem obrigatoriamente enunciar quem ou o que se é.

Uma pergunta que se coloca de maneira importante: será que não "resta" nada que vibre no "interior" deste sujeito que o faça resistir a essas formas de governo que o impõem a agir em conformidade com os regimes de pessoa preestabelecidos?

De acordo com Rose (2001a), não sobra nada nesse "interior" tecido trabalhosamente por quatro séculos, como nos descreve Figueiredo (1992). Até a resistência que alguns fazem às formas de vida que são compelidos a adotar, não emerge de um "eu profundo". Para explicar esse movimento não raro de oposição a um regime particular para a conduta da própria conduta, o autor afirma que não 
precisa recorrer a qualquer teoria sobre as supostas forças inerentes em cada ser humano, já que os seres humanos não são sujeitos unificados governados por algum regime coerente de governo que produza pessoas da forma que imagina.

Eles vivem suas vidas em um constante movimento entre diferentes práticas, as quais os subjetivam de diferentes maneiras. As pessoas são, nessas diferentes práticas, interpeladas como diferentes tipos de seres humanos, imaginadas como diferentes tipos de seres humanos, influenciadas como se fossem diferentes tipos de seres humanos (ROSE, 2001a, p. 48).

Basta lembrar que existem técnicas que fazem com que as pessoas se pensem como singulares e dignas de respeito, e práticas que, em contraposição, insistem em produzi-las como sujeitos disciplinares, ao mesmo tempo dóceis e úteis, para entender que fazer resistência a uma posição identitária não é algo surpreendente. Quer dizer, resistir não significa escapar das malhas do poder, mas continuar nela de outra maneira, capturado por outro conjunto de forças que se entrecruzam e também estabelecem modos de ser possíveis e delimitados e isso se dá na medida em que se resiste a uma determinada maneira de ser, agenciada em certos dispositivos, e se sujeita a outra(s).

Concebendo o ser humano como alvo de uma multiplicidade de trabalhos, a "interioridade", tão perseguida pelas "práticas psi" para ser diagnosticada, "não é aquela de um sistema psicológico, mas a de uma superfície descontínua, de uma espécie de dobramento, para dentro, da exterioridade" (ROSE, 2001a, p. 49). A metáfora da dobra, proposta por Gilles Deleuze (2006) indica uma relação com aquilo que estaria "dentro" do ser humano sem que esse "dentro" fosse considerado um interior essencial, mas "simplesmente um dobramento de um exterior" (DELEUZE, 2006, p. 50) e um dobramento sempre suscetível a um desdobramento.

A partir da noção de dobra, considera-se o ser humano como atravessado por diversas forças, sendo algumas capazes de fazê-lo dobrar, curvar sobre elas, como se pudesse apropriar-se das que funcionam como força de autoridade e que, portanto, o afetam, tomando-as para si como parte de si, mesmo que temporariamente. Determinadas injunções, conselhos, técnicas, hábitos, rotinas podem funcionar dessa forma, como instrumentos por meio dos quais o ser humano constitui a si próprio em diferentes práticas e relações. Entendendo o processo de subjetivação como curvaturas ou dobramentos de forças que dificilmente se mantêm estáveis ou permanentes para o sujeito, é possível finalmente pensar a subjetivação não só como o recurvar sobre si tais forças, voltando-as sobre si próprio, mas também a possibilidade de resistir a elas, optando por outras. Assim, "a genealogia da subjetivação precisa pensar o ser humano como uma maquinação - um híbrido de carne, artefato, saber, paixão e técnica" (ROSE, 2001a, p. 50).

Segundo Levy (2003) subjetivação é construir pregas, dobras que são vergadas, dobrando o Fora (devires). Ou seja, há modos de viver (como forças) circulando transversalmente que, em algum momento, dobram-se (afetam-nos) 
tornando-nos um sujeito que "se" pretende humano (ter uma vida). Essa tal vida humana que flui na hiperposição de forças que se entrelaçam em redes e nos pescam no oceano da vida. Vida que flui sempre nesse embate de composição de forças-devires. A vida imprevisível.

A Psicologia emerge em um jogo de forças que se atualizam a cada "caso" estudado. Ela torna-se um dispositivo porque provoca um acontecimento: materializam-se em práticas ordenadoras, ou seja, seu saber tem efeito de verdade e por isso cria práticas, que começam a ter uma regularidade, viram uma norma, mesmo que não esteja escrita em alguma lei ou estatuto. Por exemplo, é comum no estudo de documentos jurídicos ver que o relatório da Psicologia se remete com frequência ao termo "família desestruturada", leia-se família pobre, com pais que trabalham fora do lar, deixam suas crianças com vizinhos ou sós etc. ${ }^{7} \mathrm{~A}$ caracterização de "família desestruturada" deve ser vista como uma classificação que funciona como mecanismo estratégico com vistas a um governo da população. No caso exemplificado, são famílias ordenadas como população em que se cria o acontecimento de serem pobres e isso lhes impede de cuidarem de seus filhos. Essa "noção de família" é uma política de verdade que efetivas relações de poder-saber.

Como mostrou Foucault (1980) em A Vontade de Saber, a verdade advém de um sistema de provas. A função da psicologia corre o risco de contribuir com a padronização de um modo de viver (vivido como família tradicional, por exemplo), que quando não é vivido conforme o padrão torna-se prova de uma patologia. Psicólogos podem funcionar como testemunhas e examinadores das formas de governo da população.

São questões para a Psicologia, que não são novas, considerando as reflexões de autores clássicos. Relativamente novas são as inserções da Psicologia nos sistemas públicos (educação, saúde, justiça), mantendo-se alheia a questões que lhe pedem mais criatividade e menos normalização.

\section{Notas}

${ }^{1} \mathrm{O}$ "biopoder" refere-se a mais uma forma de governo, descrito por Foucault, para um controle/ gestão mais efetivo dos corpos, sendo que em nível de população, da espécie humana, e não mais em nível de indivíduo. Ex.: o controle dos índices de natalidade ou mortalidade da população em uma cidade.

${ }^{2}$ Ano da publicação do segundo volume da História da Sexualidade, os uso dos prazeres.

3 "Universais antropológicos" são definidos por Foucault (2004, p. 237) como "tudo o que nos é proposto em nosso saber, como sendo de validade universal, quanto à natureza humana ou às categorias que se podem aplicar ao sujeito". Isso se aplica às teses sobre a natureza social ou genética que citamos acima.

${ }^{4}$ Trata-se de um termo ao mesmo tempo conceitual e metodológico que situaos saberes, como aponta Castro (2009, p.185), no âmbito de lutas e relações de podere governo. Desta forma, devese tratar saberes não como antagônicos, como deseja o método dialético (busca a dominação de uns sobre os outros), mas como "agonismo": na vida humana há resistências e deslocamentos que buscam vidas mais libertárias, sem que isso signifique um modelo de vida feliz a ser seguido. Foucault (1979) explicita que a genealogia estuda o poder em sua positividade, ou seja, em sua capacidade de criar (domínios, saberes, modos de vida).

${ }^{5}$ No trabalho de Bonfim (2004), é possível percebemos que esta discussão é de suma importância para o campo da Psicologia Social p.ex. 
${ }^{6}$ Segundo Larrosa (1994), essa citação foi retirada de um texto que Foucault escreveu com o pseudônimo de Maurice Florence, no Dictionaire des Philosophes. Paris, PUF, 1984, p. 297-298.

${ }^{7}$ Avarca (2011) realizou pesquisa em processos judiciais em Vara de Família em São Paulo, que indicou essa situação

\section{REFERÊNCIAS}

AVARCA, C. A. de C. A noção de família em processos judiciais: uma análise a partir de casos de violência sexual infantil. 2011. 152 f. Dissertação (Mestrado em Psicologia Social)-Pontifícia Universidade Católica de São Paulo, São Paulo, 2011.

BECK, U. Risk Society: towards a new modernity. London: Sage, 1993.

BONFIM, E. M. Históricos Cursos de Psicologia Social no Brasil. Psicologia \& Sociedade; v. 16, n. 2, p. 32-36, maio/ago.2004.

BUTLER, J. Cuerpos que importan: sobre los límites materiales y discursivos del "sexo". 2. ed. Buenos Aires: Paidós, 2008.

CASTRO, E. Vocabulário de Foucault. Tradução de Ingrid Müller Xavier. Belo Horizonte: Autêntica, 2009.

DELEUZE, G.; GUATTARI, F. Mil Platôs: capitalismo e esquizofrenia. Rio de Janeiro: Editora 34, 1995. v. 2.

DELEUZE, G. Foucault. Tradução de C. S. Martins. São Paulo: Brasiliense, 2006.

FERREIRA, A. B. H. Mini-Aurélio Século XXI: o minidicionário da língua portuguesa. 4. ed. Rio de Janeiro: Nova Fronteira, 2000.

FIGUEIREDO, L. C. M. A invenção do psicológico: quatro séculos de subjetivação (1500-1900). São Paulo: EDUC; Escuta, 1992.

FIGUEIREDO, L. C. M.; SANTI, P. L. R. de. Psicologia, uma (nova) introdução: uma visão histórica da Psicologia como ciência. 2. ed. São Paulo: EDUC, 2004.

FOUCAULT, M. A governamentalidade. In: . Micro física do poder. Rio de Janeiro: Graal, 1979. p. 277-293.

FOUCAULT, M. História da sexualidade: a vontade de saber. Rio de Janeiro: Graal, 1980. v. I.

FOUCAULT, M. História da Sexualidade: o uso dos prazeres. Rio de Janeiro: Graal, 1984. v. II. 
FOUCAULT, M. A arqueologia do saber. Rio de Janeiro: Forense, 1987.

FOUCAULT, M. La psychologie de 1850 a 1950. In: HUISMAN, D.; WEBER, A. Histoire de la philosophie européenne. Traducción: Hernán Scholten. Paris: Fischbacher, 1957. t. II. Reproduzido In: FOUCAULT, M., Dits et écrits. Paris: Gallimard, 1994a. t. I, p. 120-137.

FOUCAULT, M. As técnicas de si. Tradução de Karla Neves e Wanderson Flor do Nascimento. Dits et écrits. Paris: Gallimard, 1994b. v. IV, p. 783-813, Disponível em <http://vsites.unb.br/fe/tef/filoesco/foucault/tecnicas.pdf>. Acesso em: 18 fev. 2010.

FOUCAUlT, M. O Sujeito e o Poder. Tradução de Vera Porto Carrero. In: DREYFUS, H.; RABINOW, P. Michel Foucault, uma trajetória filosófica: para além do estruturalismo e da hermenêutica. Rio de Janeiro: Forense Universitária, 1995. p. 231-249.

FOUCAULT, M. A ordem do discurso. 3. ed. Tradução de L. F. A. Sampaio. São Paulo: Loyola, 1996.

FOUCAULT, M. Resumos dos Cursos do Collège de France (1970-1982). Rio de Janeiro: J. Zahar, 1997.

FOUCAULT, M. Foucault. In: MOTTA M. B. (Org.). Ética, sexualidade, política. Rio de Janeiro: Forense Universitária, 2004. v. 5, p. 234-239. Coleção Ditos \& Escritos.

FOUCAULT, M. Omnes et singulatim: uma crítica da razão política. In: MOTTA, M. B. (Org.). Estratégia poder-saber. Rio de Janeiro: Forense Universitária, 2006. v. IV.p. 355-385.Coleção Ditos \& Escritos.

FOUCAULT, M. Segurança, território, população. Tradução de E. Brandão. São Paulo: Martins Fontes, 2008.

HALL, S. A identidade cultural na pós-modernidade. Tradução de Guacira Lopes Louro e Tomaz Tadeu Silva.11 ed. Rio de Janeiro: DP\&A, 2006.

HARVEY, D. Condição pós-moderna: uma pesquisa sobre as origens da mudança cultural. 16. ed. São Paulo: Loyola, 1992.

HARAWAY, D. Ciencia, cyborgues y mujeres: la reinvención de la naturaleza. Madrid: Cátedra, 1996.

LARROSA, J. Tecnologias do eu e educação. In: SILVA, T. T. (Org.). O Sujeito da Educação: estudos foucaultianos. Petrópolis: Vozes, 1994. p. 35-86 
LATOUR, B. Jamais fomos modernos: ensaio de Antropologia Simétrica. Rio de Janeiro: Editora 34, 1996.

LEVY, T. S. A experiência do fora: Blanchot, Foucault e Deleuze. Rio de Janeiro: Relume-Dumará, 2003.

MACHADO, R. Por uma genealogia do poder (introdução). In: FOUCAULT, M. Microfísica do poder. Rio de Janeiro: Graal, 1982. p. VII-XXIII.

MACHADO, R. Deleuze, a arte e a filosofia. Rio de Janeiro: J. Zahar, 2009.

MARTON, S. Décadence, um diagnóstico sem terapêutica: sobre a interpretação de Wolfgang Müller-Lauter. Cadernos Nietzsche, v. 6, 1999. p. 3-9.

MÜLLER-LAUTER, W. A doutrina da vontade de poder em Nietzsche. Tradução de O. Giacóia Junior. São Paulo: Annablume, 1997.

PRADO FILHO, K. Uma história crítica da subjetividade no pensamento de Michel Foucault. In: SOUZA, P.; FALCÃO, L. F. Michel Foucault: perspectivas. Rio de Janeiro: Achiamé, 2005. p. 41-50.

PRADO FILHO, K.; TRISOTTO, S. A Psicologia como disciplina da norma nos escritos de M. Foucault. Revista Aulas - Dossiê Foucault, n. 3, dez. 2006/mar. 2007. Disponível em: < http://www.unicamp.br/ aulas/pdf3/KLEBER.pdf >. Acesso em: 12 mar. 2009.

PRECIADO, B. Testoyonqui. Madri: Esparsa, 2008.

RAUTER, C. Criminologia e subjetividade no Brasil. Rio de Janeiro: Revan, 2003.

ROSE, N. Como se deve fazer a história do eu? Educação \& Realidade. Porto Alegre, v. 26, n. 1, p. 33-57, jan./jun. 2001a.

ROSE, N. Inventando nossos eus. In: SILVA, T. T. (Org.). Nunca fomos humanos: nos rastros do sujeito. Belo Horizonte: Autêntica, 2001b. p. 137-204.

SÁNCHEZ, L. G.; MARTÍNEZ, L. M. M.; RICO, F. J. Psicologia, identidade e política nas tecnologias de governo neoliberais. Psicologia \& Sociedade, São Paulo, v. 18, n. 1, p.7-14, 2006.

SPINK, M. J. Linguagem e produção de sentidos no cotidiano. Porto Alegre: EDIPUCRS, 2004. 
TEDESCO, S. As práticas do dizer e os processos de subjetivação. Interação em Psicologia, Curitiba, v. 10, n. 2, p. 357-362, jul./dez. 2006.

WEINMANN, A. Dispositivo: um solo para a subjetividade. Psicologia e Sociedade. Revista da Associação Brasileira de Psicologia Social - ABRAPSO, Florianópolis, v. 18, n. 3, p. 16-22, set./dez. 2006.

ZAMORA, M. H. Os corpos da vida nua: sobreviventes ou resistentes? Lat. Am. j. Fundam. Psychopathol. Online, São Paulo, v. 5, n. 1, p. 104-117, 2008.

Recebido em: 02 de agosto de 2010 Aceito em: 22 de junho de 2011 